\title{
Core-Shell Structure of a Silicon Nanorod/Carbon Nanotube Field Emission Cathode
}

\author{
Bohr-Ran Huang, ${ }^{1}$ Ying-Kan Yang, ${ }^{1}$ Tzu-Ching Lin, ${ }^{1}$ and Wen-Luh Yang ${ }^{2}$ \\ ${ }^{1}$ Graduate Institute of Electro-Optical Engineering and Department of Electronic Engineering, \\ National Taiwan University of Science and Technology, Taipei 106, Taiwan \\ ${ }^{2}$ Department of Electronic Engineering, Feng Chia University, Taichung 407, Taiwan \\ Correspondence should be addressed to Tzu-Ching Lin, d9702308@mail.ntust.edu.tw \\ Received 30 June 2011; Revised 23 August 2011; Accepted 24 August 2011 \\ Academic Editor: Linbao Luo
}

Copyright ( $) 2012$ Bohr-Ran Huang et al. This is an open access article distributed under the Creative Commons Attribution License, which permits unrestricted use, distribution, and reproduction in any medium, provided the original work is properly cited.

A novel core-shell structure of silicon nanorods/carbon nanotubes (SiNRs/CNTs) is developed for use in field emission cathodes. The CNTs were synthesized on SiNRs, using the Ag-assisted electroless etching technique to form the SiNRs/CNT core-shell structure. This resulting SiNRs/CNT field emission cathode demonstrated improved field emission properties including a lower turn-on electric field $E_{\text {on }}\left(1.3 \mathrm{~V} / \mu \mathrm{m}, 1 \mu \mathrm{A} / \mathrm{cm}^{2}\right)$, a lower threshold electric field $E_{\text {th }}\left(1.8 \mathrm{~V} / \mu \mathrm{m}, 1 \mathrm{~mA} / \mathrm{cm}^{2}\right)$, and a higher enhancement factor $\beta$ (2347). These superior properties indicate that this core-shell structure of SiNRs/CNTs has good potential in field emission cathode applications.

\section{Introduction}

Carbon nanotubes (CNTs) have unique physical and chemical properties such as a high aspect ratio, small radius of curvature, exceptional chemical inertness, excellent environmental stability, and high mechanical strength [1-5]. Given their high field emission current density at low electric field and highly stable current, CNTs can be applied to field emission cathodes [6]. However, the field emission properties of densely packed CNTs are affected by the field-screening effect among neighboring nanotubes [7]. Patterning the alignment of CNTs has been found to improve field emission properties [8-11]. Combining CNTs and other nonplanar substrates has also been used to improve field emission properties, for example, on tungsten tips [12], nanocrystalline diamond films [13], and silicon nanostructures [14-17]. CNTs have been grown on the top of silicon nanowires (SiNWs), performing the $E_{\text {on }}$ of $2 \mathrm{~V} / \mu \mathrm{m}\left(10 \mu \mathrm{A} / \mathrm{cm}^{2}\right)$ [15]. These structures could be used to effectively improve field emission properties. CNT field emission cathodes can be fabricated by various methods such as direct growth, electrophoresis, screen printing, the spray method, and composite plating [18-22].

In this work, the CNTs were grown directly onto the SiNRs, forming the core-shell structure of a SiNRs/CNTs field emission cathode by thermal chemical vapor deposition. Investigation of the field emission properties of SiNRs, CNTs, and the SiNRs/CNTs field emission cathode showed that this core-shell structure of SiNRs/CNTs improves the cathode field emission properties.

\section{Experimental}

The SiNRs were synthesized on a p-type $(1-10 \Omega \mathrm{cm}, \mathrm{B}$ doped, $520 \mathrm{um}$ ) Cz silicon (100) wafer using the Ag-assisted electroless etching technique [23]. First, the wafer was cleaned ultrasonically for $20 \mathrm{~min}$ in both acetone and isopropyl alcohol. The cleaned silicon wafer was then immersed in a mixture of $5 \mathrm{~mol} / \mathrm{L}$ aqueous hydrofluoric acid (HF) and $0.02 \mathrm{~mol} / \mathrm{L}$ silver nitrate $\left(\mathrm{AgNO}_{3}\right)$ solution for 3 hours at room temperature. Following the electroless etching process, 


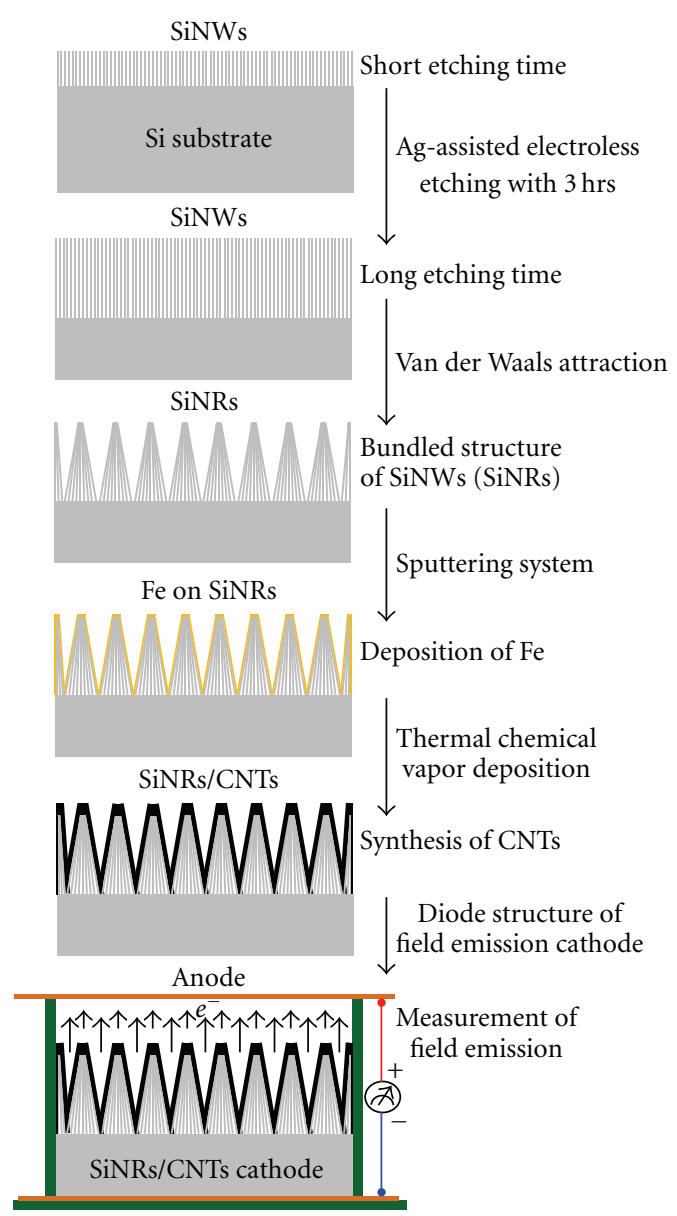

FIGURE 1: Schematic diagram of the procedures for fabricating the core-shell structure of SiNRs/CNTs field emission cathodes.

the high-density tree-like dendritic structures of silver films were removed using $30 \mathrm{wt} \% \mathrm{HNO}_{3}$ aqueous solution for $60 \mathrm{~s}$. Finally, the samples were rinsed with deionized water and airdried.

The as-prepared SiNRs and silicon substrate were deposited with iron (Fe) catalyst layers and immediately placed in a quartz tube furnace to grow CNTs. Furnace conditions were $700^{\circ} \mathrm{C}$ at atmospheric pressure with a mixed gas of $\mathrm{N}_{2}$ and $\mathrm{C}_{2} \mathrm{H}_{2}(10: 3)$ using the thermal chemical vapor deposition method.

The surface morphologies of films were characterized by field emission scanning electron microscopy (FESEM, JEOL JSM-6700F, operated at $15 \mathrm{kV}$ ) and transmission electron microscopy (TEM, Philips Tecnai F20 G2 FEI-TEM). The bonding structures of CNTs were analyzed using microRaman spectroscopy with excitation of spectrum $514 \mathrm{~nm}$. The field emission measurements were performed using parallel-plate geometry with a gap of $150 \mu \mathrm{m}$ between the anode (copper) and the cathode (samples) in a vacuum chamber with a base pressure of about $1 \times 10^{-6}$ Torr. A Keithley 237 was used to provide variable dc voltages and collect electric current across the specimen, and the emission measurement area was $10 \times 10 \mathrm{~mm}^{2}$. Figure 1 schematically

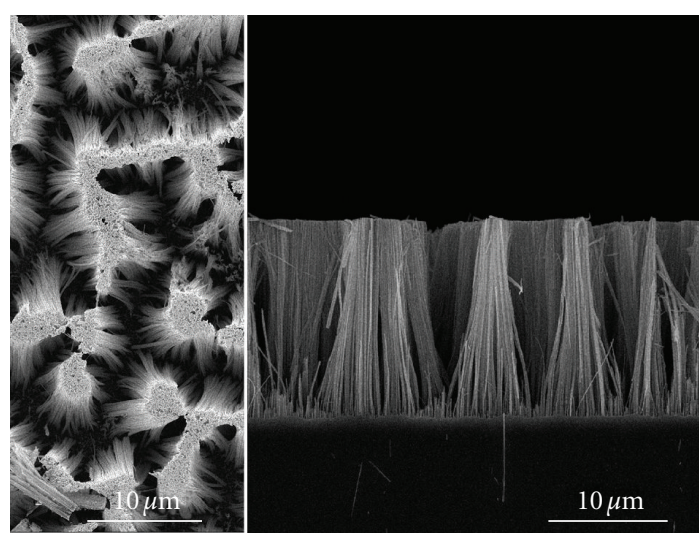

(a)

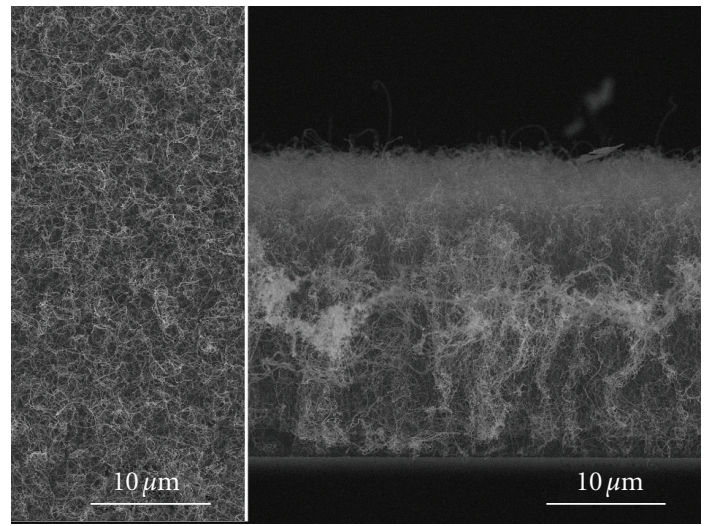

(b)

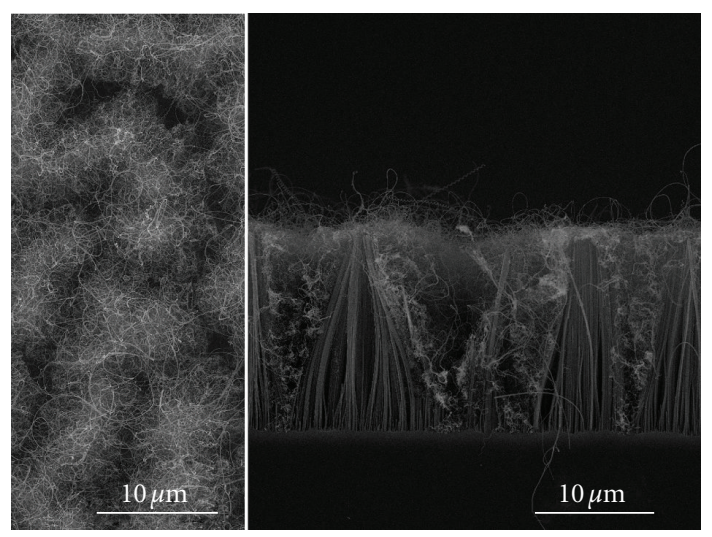

(c)

FigURE 2: SEM images of surface and cross-section morphology of (a) SiNRs, (b) CNTs, and (c) SiNRs/CNTs.

diagrams the procedures for fabricating the core-shell structure of the SiNRs/CNTs field emission cathode.

\section{Result and Discussion}

Figure 2 shows the SEM images of the surface and crosssection morphology of the SiNRs, CNTs, and SiNRs/CNTs films. During the long etching time the silicon nanowires (SiNWs) take on a bundled structure, which is attributed to 


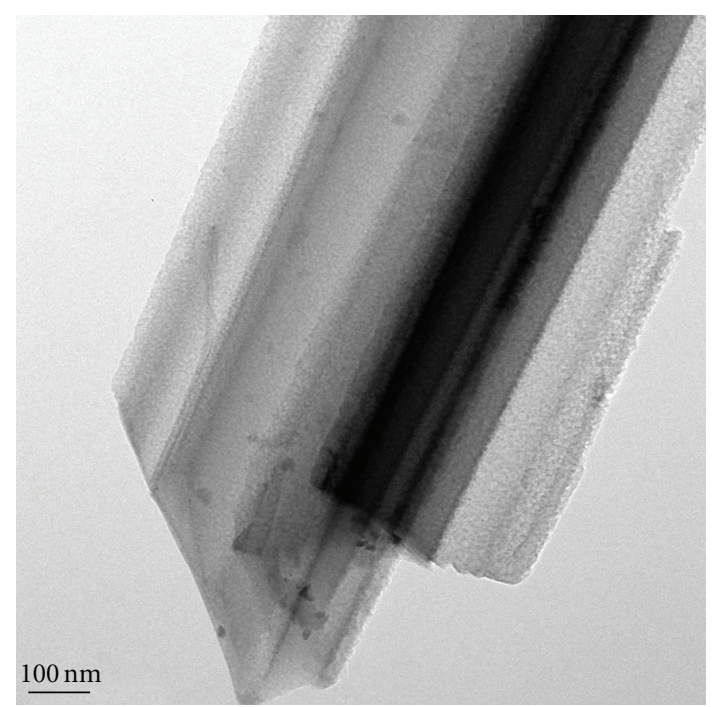

(a)

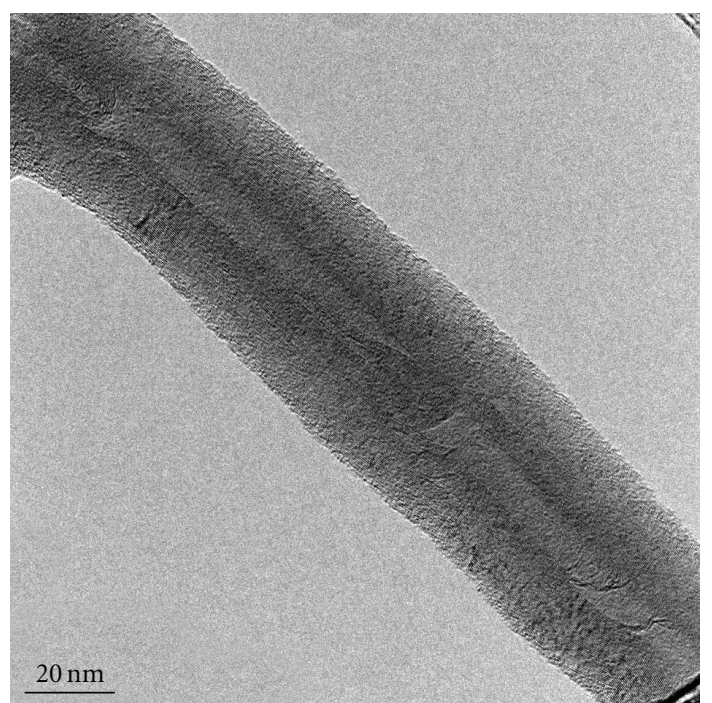

(b)

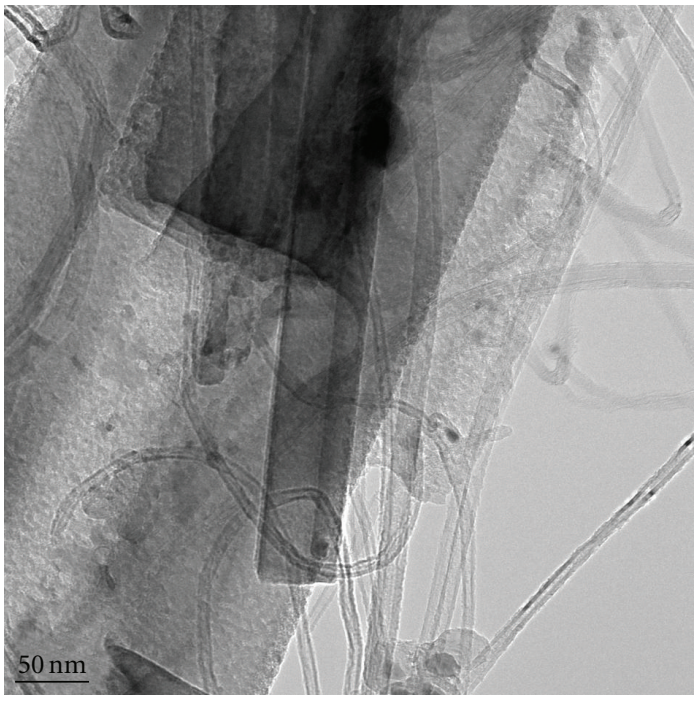

(c)

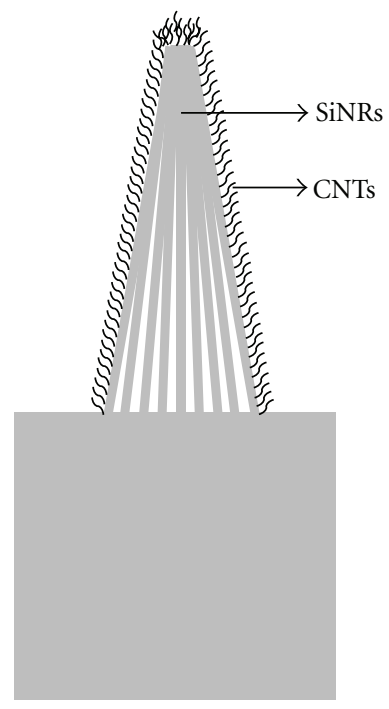

(d)

Figure 3: TEM images of (a) SiNR, (b) CNT, and (c) core-shell structure of SiNRs/CNTs, and (d) schematic diagram of the SiNRs/CNTs.

the strong SiNWs van der Waals attraction [24]. As a result, in this study, the SiNWs bundle structure is denominated the SiNRs. The SiNRs are separated from each other and are held perpendicular to the sample surface at an average height of $\sim 17 \mu \mathrm{m}$. A large quantity of highly aligned CNTs film was deposited on the silicon substrate, as shown in Figure 2(b). Ten min growth produces a CNTs film with a thickness of $\sim 26 \mu \mathrm{m}$. The physical deposition is limited to the nanoscale which causes discontinuous deposition of the Fe catalyst layer on the SiNRs. This suggests that the top of the SiNRs is covered by a thicker Fe layer than their sidewalls and bottom. Hence, the numerous entangled CNTs form the nest-shaped assemblages of CNTs on the top of each SiNRs, and the CNTs are also synthesized on the SiNRs side-walls to form a coreshell structure, as shown in Figure 2(c).

Figures $3(\mathrm{a})-3(\mathrm{c})$ show the TEM images of SiNRs, CNTs, and SiNRs/CNTs. Figure $3(\mathrm{~b})$ shows a multiwall nanotube with a hollow structure and reveals the wellordered lattice fringes of the nanotube. Figure 3(c) shows that the SiNRs are surrounded by CNTs. Figure 3(d) shows the magnified schematic diagram of the core-shell structure of SiNRs/CNTs.

The Raman spectrum of CNTs typically has two characteristic peaks at around 1350 and $1580 \mathrm{~cm}^{-1}$ [25]. The $1580 \mathrm{~cm}^{-1}$ peak can be identified as the $\mathrm{G}$ band of crystalline graphite arising from its zone-center $E_{2 \mathrm{~g}}$ mode. For graphitelike materials with defects, the $1350 \mathrm{~cm}^{-1}$ peak is identified as the $\mathrm{D}$ band, which is activated due to defects in and disorder of the carbonaceous material. Thus, the smaller relative intensity ratio of the $\mathrm{D}$ and $\mathrm{G}$ bands $\left(I_{\mathrm{D}} / I_{\mathrm{G}}\right)$ implies a better graphite structure and a higher degree of graphitization. In comparison with the localized electrons in $\sigma$ bonds on CNTs, the delocalized electrons in the $\pi$ orbital of the $\mathrm{sp}^{2}$ bond have a higher degree of mobility and are more easily 


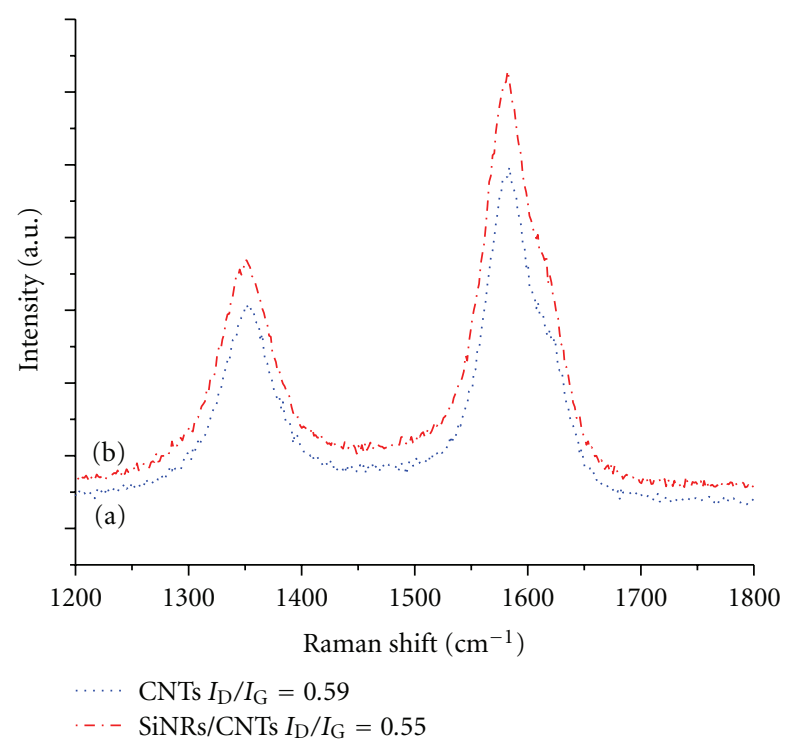

FIGURE 4: Raman spectra of (a) CNTs and (b) SiNRs/CNTs.

emitted from CNTs [26]. Therefore, greater $\mathrm{sp}^{2}$ bonding (i.e., lower $I_{\mathrm{D}} / I_{\mathrm{G}}$ ratio) would improve the field emission properties [27]. Figure 4 shows the Raman spectra of the CNTs and the SiNRs/CNTs, with respective $I_{\mathrm{D}} / I_{\mathrm{G}}$ ratios of about 0.59 and 0.55 . The core-shell structure does not affect the graphitization of the CNTs, which makes them applicable to field emission devices.

Figure 5 shows the current density-electric field $(J-E)$ plot and the corresponding Fowler-Nordheim (FN) plot. According to the FN equation, the emission current density $J=A(\beta E)^{2} \exp \left(-B \phi^{3 / 2} / \beta E\right)$, where $A$ and $B$ are constants, $E$ is the applied electric field, $\beta$ is the enhancement factor, and $\phi$ is the work function of 5 and $4.15 \mathrm{eV}$ for CNTs and SiNRs, respectively $[15,28]$. The respective $E_{\text {on }}$ at a current density of $1 \mu \mathrm{A} / \mathrm{cm}^{2}$ for the SiNRs, CNTs, and SiNRs/CNTs field emission cathodes is $4.5,2.4$, and $1.3 \mathrm{~V} / \mu \mathrm{m}$. The respective $E_{\text {th }}$ at a current density of $1 \mathrm{~mA} / \mathrm{cm}^{2}$ for CNTs and SiNRs/CNTs field emission cathodes is 4.2 and $1.8 \mathrm{~V} / \mu \mathrm{m}$. The respective enhancement factor $\beta$ of the SiNRs, CNTs, and SiNRs/CNTs field emission cathodes is estimated at about 1154,1675 , and 2347.

The field emission property with $E_{\text {th }}$ of the core-shell structure of SiNRs/CNTs is comparable to that found in previous reports. Li and Jiang. deposited CNTs on a silicon nanoporous pillar array prepared by hydrothermal etching technique [16], which provided good field emission properties with the $E_{\text {th }}$ about $1.9 \mathrm{~V} / \mu \mathrm{m}$. Qinke et al. synthesized CNTs on the top of a SiNW array prepared by Ag-assisted electroless etching [15], which showed the $E_{\text {th }}$ at about $3.3 \mathrm{~V} / \mu \mathrm{m}$. CNTs only synthesized on the top of the SiNW array, which failed to effectively enhance the field emission properties. The SiNRs/CNTs field emission cathode shows not only a high enhancement factor but also low $E_{\text {on }}$ and low $E_{\text {th }}$. The screening effect of densely packed CNTs produced among neighboring nanotubes resulted in disappointing CNTs field emission properties [29]. The core-shell structure

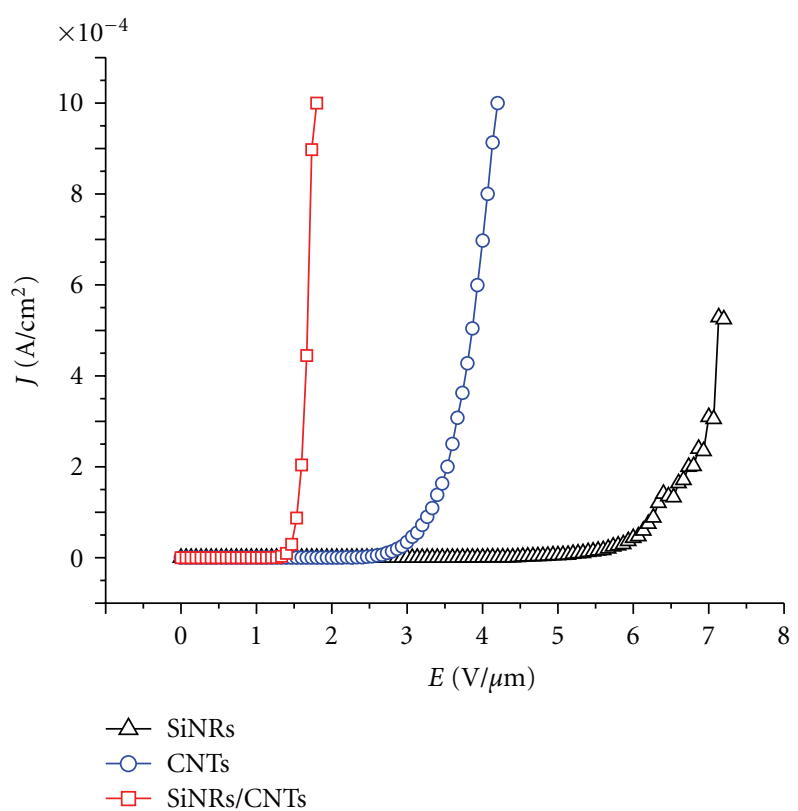

(a)

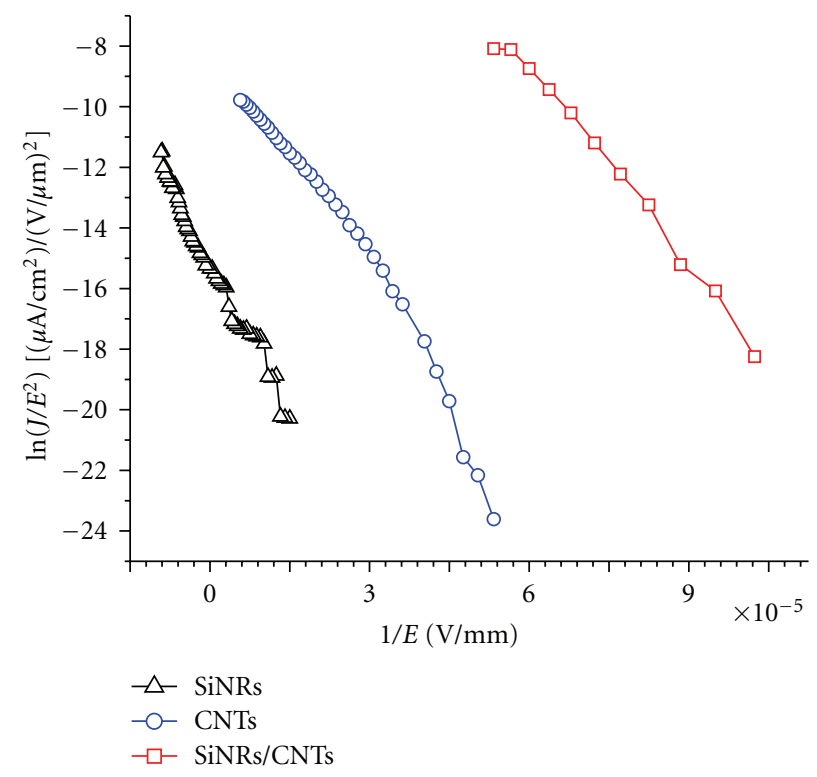

(b)

Figure 5: Field emission properties of the SiNRs, CNTs, and SiNRs/CNTs cathodes: (a) current density versus electric field $(J-E)$ plots; (b) Fowler-Nordheim plots.

of the SiNRs/CNTs reduces the density of CNTs, thus further decreasing the screening effect and improving the field emission properties. In addition, we suggest that the SiNRs/CNTs structure could reduce the work function below $5 \mathrm{eV}$. Consistent with previous reports, the lower work function of SiNRs/CNTs field emission cathode also enhances field emission properties, resulting in a higher current density, lower turn-on electric field, and higher enhancement factor [30, 31]. However, excellent field emission properties were achieved in the CNTs field emission cathode with a core-shell structure using SiNRs. Further studies are needed 
to determine the optimum SiNRs diameter and CNTs film thickness for the core-shell structure of SiNRs/CNTs cathode to promote field emission properties.

\section{Conclusion}

We developed a novel core-shell structure of SiNRs/CNTs for field emission cathodes, effectively improving field emission properties including an $E_{\text {on }}$ of $1.3 \mathrm{~V} / \mu \mathrm{m}, E_{\text {th }}$ of $1.8 \mathrm{~V} / \mu \mathrm{m}$, and $\beta$ of 2347. These improvements were attributed to the SiNRs/CNTs core-shell structure reducing the screening effect and work function. These results indicate that the core-shell structure of SiNRs/CNTs might be suitable for improved cathode of field emission displays.

\section{Acknowledgment}

This work was supported by the National Science Council of Taiwan under Grant no. 99-2221-E-011-065.

\section{References}

[1] S. Iijima, "Helical microtubules of graphitic carbon," Nature, vol. 354, no. 6348, pp. 56-58, 1991.

[2] B. I. Yakobson, C. J. Brabec, and J. Bernholc, "Nanomechanics of carbon tubes: instabilities beyond linear response," Physical Review Letters, vol. 76, no. 14, pp. 2511-2514, 1996.

[3] K. H. An, S. Y. Jeong, H. R. Hwang, and Y. H. Lee, "Enhanced sensitivity of a gas sensor incorporating single-walled carbon nanotube-polypyrrole nanocomposites," Advanced Materials, vol. 16, no. 12, pp. 1005-1009, 2004.

[4] H. Usui, H. Matsui, N. Tanabe, and S. Yanagida, "Improved dye-sensitized solar cells using ionic nanocomposite gel electrolytes," Journal of Photochemistry and Photobiology A, vol. 164, no. 1-3, pp. 97-101, 2004.

[5] W. A. De Heer, A. Châtelain, and D. Ugarte, "A carbon nanotube field-emission electron source," Science, vol. 270, no. 5239, pp. 1179-1180, 1995.

[6] Y. Liu and S. Fan, "Field emission properties of carbon nanotubes grown on silicon nanowire arrays," Solid State Communications, vol. 133, no. 2, pp. 131-134, 2005.

[7] L. Nilsson, O. Groening, C. Emmenegger et al., "Scanning field emission from patterned carbon nanotube films," Applied Physics Letters, vol. 76, no. 15, pp. 2071-2073, 2000.

[8] H. J. Jeong, S. C. Lim, K. S. Kim, and Y. H. Lee, "Edge effect on the field emission properties from vertically aligned carbon nanotube arrays," Carbon, vol. 42, no. 14, pp. 3036-3039, 2004.

[9] J. S. Suh, K. S. Jeong, J. S. Lee, and I. Han, "Study of the fieldscreening effect of highly ordered carbon nanotube arrays," Applied Physics Letters, vol. 80, no. 13, p. 2392, 2002.

[10] R. C. Smith and S. R. P. Silva, "Maximizing the electron field emission performance of carbon nanotube arrays," Applied Physics Letters, vol. 94, no. 13, Article ID 133104, 3 pages, 2009.

[11] S. H. Jo, Y. Tu, Z. P. Huang, D. L. Carnahan, D. Z. Wang, and Z. F. Ren, "Effect of length and spacing of vertically aligned carbon nanotubes on field emission properties," Applied Physics Letters, vol. 82, no. 20, pp. 3520-3522, 2003.

[12] P. N. Hong, B. H. Thang, N. T. Hong, S. Lee, and P. N. Minh, "Electron field emission characteristics of carbon nanotube on tungsten tip," Journal of Physics: Conference Series, vol. 187, no. 1, 5 pages, 2009.

[13] K. J. Liao, W. L. Wang, C. Z. Cai, J. W. Lu, and C. G. $\mathrm{Hu}$, "Investigation on field electron emission from carbon nanotubes on nanocrystalline diamond films," Journal of Metastable and Nanocrystalline Materials, vol. 23, pp. 35-38, 2005.

[14] K. Matsumoto, S. Kinosita, Y. Gotoh, T. Uchiyama, S. Manalis, and C. Quate, "Ultralow biased field emitter using single-wall carbon nanotube directly grown onto silicon tip by thermal chemical vapor deposition," Applied Physics Letters, vol. 78, no. 4, pp. 539-540, 2001.

[15] S. Qinke, J. Wei, K. Wang et al., "Fabrication and field emission properties of multi-walled carbon nanotube/silicon nanowire array," Journal of Physics and Chemistry of Solids, vol. 71, no. 4, pp. 708-711, 2010.

[16] X. J. Li and W. F. Jiang, "Enhanced field emission from a nest array of multi-walled carbon nanotubes grown on a silicon nanoporous pillar array," Nanotechnology, vol. 18, no. 6, 5 pages, 2007.

[17] J. Li, W. Lei, X. Zhang, B. Wang, and L. Ba, "Field emission of vertically-aligned carbon nanotube arrays grown on porous silicon substrate," Solid-State Electronics, vol. 48, no. 12, pp. 2147-2151, 2004.

[18] Z. W. Pan, S. S. Xie, B. H. Chang, L. F. Sun, W. Y. Zhou, and G. Wang, "Direct growth of aligned open carbon nanotubes by chemical vapor deposition," Chemical Physics Letters, vol. 299, no. 1, pp. 97-102, 1999.

[19] A. R. Boccaccini, J. Cho, J. A. Roether, B. J. C. Thomas, E. Jane Minay, and M. S. P. Shaffer, "Electrophoretic deposition of carbon nanotubes," Carbon, vol. 44, no. 15, pp. 3149-3160, 2006.

[20] Y. S. Shi, C. C. Zhu, W. Qikun, and L. Xin, "Large area screenprinting cathode of CNT for FED," Diamond and Related Materials, vol. 12, no. 9, pp. 1449-1452, 2003.

[21] Y. D. Lee, K. S. Lee, Y. H. Lee, and B. K. Ju, "Field emission properties of carbon nanotube film using a spray method," Applied Surface Science, vol. 254, no. 2, pp. 513-516, 2007.

[22] B. R. Huang, T. C. Lin, Y. K. Yang, and S. D. Tzeng, "The stability of the $\mathrm{CNT} / \mathrm{Ni}$ field emission cathode fabricated by the composite plating method," Diamond and Related Materials, vol. 19, no. 2-3, pp. 158-161, 2010.

[23] T. Qiu and P. K. Chu, "Self-selective electroless plating: an approach for fabrication of functional 1D nanomaterials," Materials Science and Engineering R, vol. 61, no. 1-6, pp. 5977, 2008.

[24] K. Zhu, T. B. Vinzant, N. R. Neale, and A. J. Frank, "Removing structural disorder from oriented $\mathrm{TiO}_{2}$ nanotube arrays: reducing the dimensionality of transport and recombination in dye-sensitized solar cells," Nano Letters, vol. 7, no. 12, pp. 3739-3746, 2007.

[25] M. S. Dresselhaus, G. Dresselhaus, and P. H. Avouris, Carbon Nanotubes: Synthesis, Properties and Applications, vol. 80 of Springer Series in Topics in Applied Physics, Springer, Berlin, Germany, 2001.

[26] S. Han and J. Ihm, "Role of the localized states in field emission of carbon nanotubes," Physical Review B, vol. 61, no. 15, pp. 9986-9989, 2000.

[27] K. F. Chen, K. C. Chen, Y. C. Jiang et al., "Field emission image uniformity improvement by laser treating carbon nanotube powders," Applied Physics Letters, vol. 88, no. 19, Article ID 193127, 3 pages, 2006. 
[28] F. Zhao, D. D. Zhao, S. L. Wu, G. A. Cheng, and R. T. Zheng, "Fabrication and electron field emission of silicon nanowires synthesized by chemical etching," Journal of the Korean Physical Society, vol. 55, no. 6, pp. 2681-2684, 2009.

[29] L. Nilsson, O. Groening, C. Emmenegger et al., "Scanning field emission from patterned carbon nanotube films," Applied Physics Letters, vol. 76, no. 15, pp. 2071-2073, 2000.

[30] Z. S. Hu, F. Y. Hung, S. J. Chang et al., "Nanostructural characteristics of oxide-cap GaN nanotips by iodine-gallium ions etching," Journal of Alloys and Compounds, vol. 509, no. 5, pp. 2360-2363, 2011.

[31] Y. F. Tzeng, Y. C. Lee, C. Y. Lee, H. T. Chiu, and I. N. Lin, "Electron field emission properties on UNCD coated Sinanowires," Diamond and Related Materials, vol. 17, no. 4-5, pp. 753-757, 2008. 

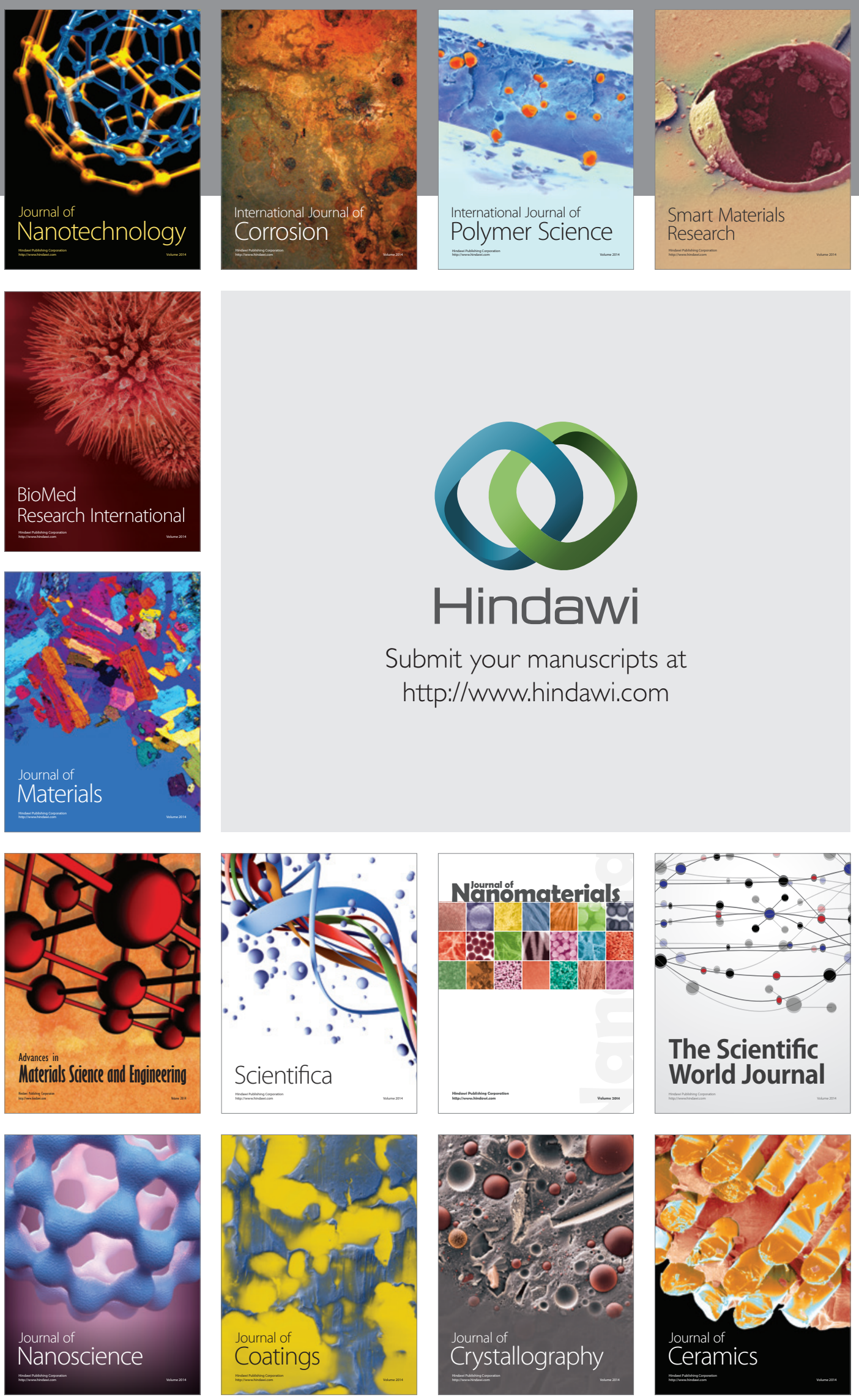

The Scientific World Journal

Submit your manuscripts at

http://www.hindawi.com

\section{World Journal}

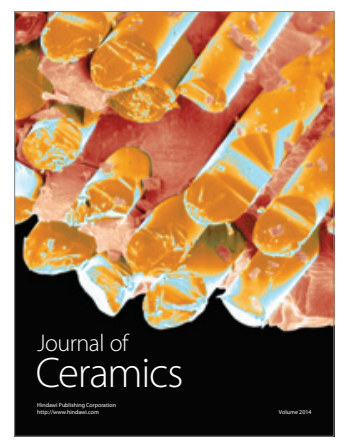

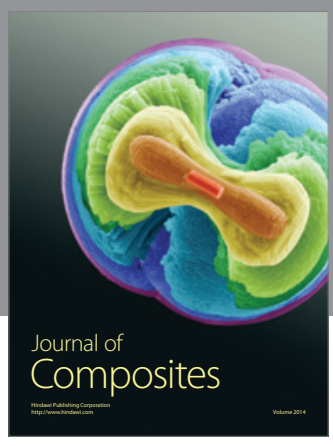
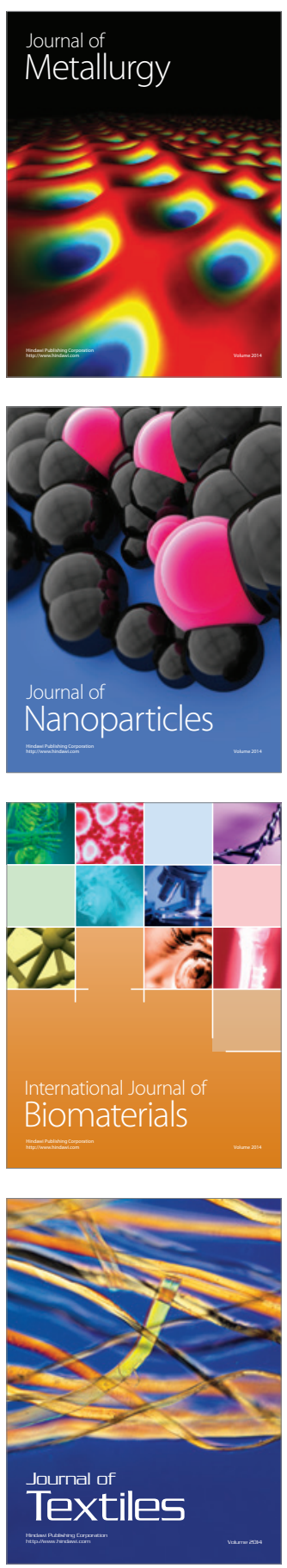